\title{
Inhibitory effects of NADH/NADPH in S9 mix on photo-muta- genicity of thiabendazole following UVA-irradiation in $E$. coli
}

\author{
Mie Watanabe-Akanuma ${ }^{1^{*}}$ and Toshihiro Ohta ${ }^{2}$ \\ ${ }^{1}$ Kureha Chemical Industry Co., Ltd. Biomedical Research Laboratories \\ 3-26-2, Hyakunin-cho, Shinjuku, Tokyo 169-8503, Japan \\ ${ }^{2}$ School of Life Science, Tokyo University of Pharmacy and Life Science \\ 1432-1 Horinouchi, Hachioji, Tokyo 192-0392, Japan
}

\begin{abstract}
Summary
Thiabendazole (TBZ), a post-harvest fungicide commonly used on imported citrus fruits, exhibited photo-mutagenicity following UVA-irradiation $(320-400 \mathrm{~nm})$ in $\operatorname{Trp}^{+}$reverse mutation assay using Escherichia coli WP2uvrA/pKM101 strain. The photo-mutagenicity was not observed in the presence of $\mathrm{S} 9 \mathrm{mix}$, a rat liver homogenate microsome fraction with co-factors for metabolic activation. We found that NADH and NADPH used as co-factor in the S9 mix efficiently suppressed the photo-mutagenicity of TBZ. This evidence strongly suggested that non-mutagenicity in the presence of S9 mix was not due to the metabolic detoxification of TBZ or the scavenging of UVA-activated TBZ by macromolecules in the S9 mix. Rather quenching effect of NADH and NADPH $(\lambda \max =338$ $\mathrm{nm}$ ) may be more responsible for suppression of UVA-activation of TBZ, because oxidized forms of $\mathrm{NAD}^{+}$and $\mathrm{NADP}^{+}$did not show inhibitory effects. Mutagenicity of the UVA-irradiated photo-mutagens such as angelicin and chlorpromazine was also suppressed by the addition of NADH or NADPH. Our present results suggest the possible underestimation in risk evaluation for photomutagenic compounds when they are assayed in the presence of S9 mix.
\end{abstract}

Keywords: photo-mutagenicity, TBZ, chlorpromazine, UVA, S9 mix

\section{Introduction}

Benzimidazole fungicides such as thiabendazole (TBZ) and benomyl are widely used because of their non-toxicity to higher plants. TBZ is approved in Japan as a post-harvest fungicide for imported citrus fruits during transport and storage. Although TBZ is reported to be cytotoxic to the spindle apparatus and mitosis in mammalian cells (Styles and Garner, 1974; Mudry de Pargament et al., 1987; Parry and Sors, 1993), it is not mutagenic in bacterial reverse mutation tests with or without metabolic activation (Cancer Assessment Document, EPA, 2000). We recently reported that $\mathrm{TBZ}$ shows potent mutagenicity following UVA-irradiation (320-400 $\mathrm{nm}$ ) for $10 \mathrm{~min}$ at 250 $\mu \mathrm{W} / \mathrm{cm}^{2}$ and that $\operatorname{Trp}^{+}$reverse mutations in Escherichia

\footnotetext{
"E-mail: akanuma@kureha.co.jp

Received: October 8, 2004, revised: January 4, 2005,

accepted: January 6, 2005

(C) Japanese Environmental Mutagen Society
}

coli WP2uvrA/pKM101 strain is more sensitive than $\mathrm{His}^{+}$ reverse mutations in Salmonella typhimurium strains TA100 and TA98 (Watanabe-Akanuma et al., 2003). The predominant mutations induced by UVA-activated TBZ were $\mathrm{G}: \mathrm{C} \rightarrow \mathrm{A}: \mathrm{T}$ transitions and $\mathrm{A}: \mathrm{T} \rightarrow \mathrm{T}: \mathrm{A}$ transversions. Since pre-irradiated TBZ solution just before adding bacterial cells did not show any mutagenicity, it seems likely that the photo-mutagenic TBZ products are unstable and/or rapidly react with other molecules before being incorporated into the cells (Watanabe-Akanuma et al., 2003). The photo-mutagenicity of TBZ in the $E$. coli strain was also observed with a fluorescent lamp, probably due to a low dose of UVA form the lamp (unpublished observation). For further investigation of the photo-mutagenic activation of TBZ by UVA-irradiation, we have conducted a screening assay to find effective inhibitors. As far as tested, several scavengers for reactive oxygen species such as ethanol, dimethyl sulfoxide, mannitol, histidine, ascorbic acid, epigallocatechin did not show apparent inhibitory effects (unpublished observation). On the other hand, the 
photo-mutagenic activation of TBZ was not observed in the presence of exogenous metabolic activation system (S9 mix) in our preliminary study. We, therefore, tested the possible suppressing effect of macromolecules like DNA, proteins, and enzymes as well as S9 fraction (rat liver microsome fraction) in this study. We report here that photo-mutagenicity of TBZ was completely abolished by the addition of NADH and NADPH which were commonly used as co-factors to prepare the S9 mix, but not by the S9 fraction or other co-factor components, suggesting a mechanism other than metabolic detoxification of TBZ.

\section{Materials and Methods}

\section{Bacterial strain, media, and chemicals}

E. coli strain WP2uvrA/pKM101 (trpE65, uvrA155, malB15, lon-11, sulA1) was used for $\operatorname{Trp}^{+}$reverse mutation assay. Bacteria were cultured in Oxoid nutrient broth No. 2 at $37^{\circ} \mathrm{C}$. Minimal glucose agar plates, and top agar for the $\operatorname{Trp}^{+}$reversion assay were described previously (Watanabe-Akanuma et al., 2003). S9 mix consisted of $10 \%$ rat liver homogenate $\mathrm{S} 9$ fraction, $4 \mathrm{mM} \mathrm{NADH}, 4$ mM NADPH, 5 mM glucose-6-phosphate (G-6-P), $33 \mathrm{mM}$ $\mathrm{KCl}, 8 \mathrm{mM} \mathrm{MgCl}_{2}, 100 \mathrm{mM}$ sodium phosphate buffer $(\mathrm{pH}$ 7.4), according to the Guideline for Screening Toxicity Testing in Chemicals, Japan (1997).

Thiabendazole [TBZ, 2-(thiazol-4-yl) benzimidazole, CAS Registry number 148-79-8, (chemical structure in Fig. 1)], chlorpromazine hydrochloride [CAS No. 69-09-0, (chemical structure in Fig. 3 right)], dimethyl sulfoxide (DMSO), L-cysteine, pyridoxal hydrochloride, bovine serum albumin (BSA) and salmon sperm DNA were purchased from Wako Pure Chemical Industries, Japan. $\beta$ $\mathrm{NADH}$ and $\beta$-NADPH (reduced forms), $\beta$-NAD ${ }^{+}$and $\beta$ $\mathrm{NADH}^{+}$(oxidized forms), G-6-P, S9 fraction, and co-factors mix solution were purchased from Oriental Yeast Co., Japan. Angelicin [CAS No. 523-50-2, (chemical structure in Fig. 3 left)], glutathione (reduced forms), and superoxide dismutase (SOD) from bovine erythrocytes were purchased from Sigma-Aldrich Co. MO, USA. Catalase from beef liver was purchased from Roche Diagnostics Co., IN, USA. UV absorption spectra from $280-400 \mathrm{~nm}$ of $\mathrm{NADH}$, $\mathrm{NADPH}$, and TBZ were measured using a U-2000A spectrophotometer (Hitachi Ltd., Japan).

\section{UVA-irradiation}

A black-light fluorescent lamp (National Black Light Blue, FL15BL-B, 15W, Matsushita Electric Industrial Co., Japan) that emitted wavelengths of 300-400 nm was used as the UVA source. To filter out UVB wavelengths below $320 \mathrm{~nm}$, which are weakly mutagenic to the tester strain, a 5 -mm thick soft glass plate was used. UVA was irradiated from a distance of $22 \mathrm{~cm}$ at $250 \mu \mathrm{W} / \mathrm{cm}^{2}$ (UVX Radiometer, Model UVX-36, Ultra-Violet Products, Upland, CA, USA) for 10 min on a 24 -well multiplate with lid.

\section{Mutagenicity assay}

Bacteria were grown overnight in nutrient broth to a density of $1-3 \times 10^{9}$ cells $/ \mathrm{mL}$. A $0.1 \mathrm{~mL}$ aliquot of overnight culture was added to each well of a 24 -well multiplate containing $0.5 \mathrm{~mL}$ of either S9 mix or $100 \mathrm{mM}$ sodium phosphate buffer ( $\mathrm{pH} 7.4)$. TBZ solution $(2.5-20 \mu \mathrm{L})$ dissolved in DMSO at a concentration of $10 \mathrm{mg} / \mathrm{mL}$ was added at doses of 25-200 $\mu \mathrm{g}$, and mixed well by pipetting. There was no precipitation of TBZ. The mixture was irradiated by UVA for $10 \mathrm{~min}$ at room temperature. Photomutagens, angelicin (Venturini et al., 1980; 1981) and chlorpromazine (Ciulla et al., 1986; Oppenländer, 1988; Gocke, 1996) dissolved in DMSO and sterile water respectively, were also used. In other experiments, one of the following compounds was added to the well containing phosphate buffer, TBZ, and bacteria: 1-100 $\mu \mathrm{g}$ of DNA, BSA, catalase, and SOD (10 $\mu \mathrm{L}$ of $0.1-10 \mathrm{mg} / \mathrm{mL}$ solutions), $1-50 \mu \mathrm{L}$ of S9 fraction, $0.1-3 \mu \mathrm{mol} \mathrm{NADH}$, $\mathrm{NADPH}, \mathrm{NAD}^{+}$, and $\mathrm{NADP}^{+}(10 \mu \mathrm{L}$ of $10-300 \mu \mathrm{mol} / \mathrm{mL}$ solutions). After the mixtures were irradiated by UVA for $10 \mathrm{~min}$, they were transferred to $2 \mathrm{~mL}$ of molten top agar in a test tube kept at $46^{\circ} \mathrm{C}$, and immediately poured onto a minimal glucose agar plate. Plates were incubated for 2 days at $37^{\circ} \mathrm{C}$ and the number of $\operatorname{Trp}^{+}$revertant colonies was counted. Experiments were conducted with duplicate plates for each dose and triplicate plates for the control. Data presented in the figures are the averages of duplicate or triplicate plates.

\section{Results}

Suppressing effect of macromolecules such as proteins and DNA in the irradiation mixture on photo-mutagenicity of TBZ was first investigated. At a dose of $150 \mu \mathrm{g}(0.75$ $\mu$ mol) TBZ, UVA-irradiation for $10 \mathrm{~min}$ caused about 7fold increase in the number of $\operatorname{Trp}^{+}$revertants of WP2uvrA/pKM101 over the corresponding control plates, while neither TBZ nor UVA alone was mutagenic (Table 1). Addition of sermon sperm DNA, BSA, reactive oxygen eliminating enzymes (SOD and catalase) up to a dose of $100 \mu \mathrm{g}$ did not cause any suppressing effects. On the other hand, photo-mutagenicity of TBZ was largely reduced in the presence of S9 mix, but not S9 fraction alone (Table 1), suggesting either that the UVA-activated TBZ easily reacted with compounds in the S9 mix before entering the cells, or that the metabolites of TBZ were no longer photo-mutagenic. Further investigations, however, revealed that the photo-mutagenicity of TBZ was completely inhibited by the addition of $0.5 \mathrm{~mL}$ of co-factors solution alone as shown in Fig. 1. The results implied that the lack of photo-mutagenicity of TBZ in the presence of S9 mix was not due to simple metabolic detoxification of TBZ. Among the ingredients (G-6-P, NADH, NADPH, $\mathrm{KCl}$, and $\mathrm{MgCl}_{2}$ ) of co-factors, $\mathrm{NADH}$ and $\mathrm{NADPH}$ were found to be responsible for the suppressing effects. As 
Table 1 Effect of macromolecules on the photo-mutagenicity of TBZ with UVA-irradiation

\begin{tabular}{lrrccc}
\hline $\begin{array}{l}\text { Compound } \\
\text { (Dose) }\end{array}$ & $\begin{array}{r}\text { TBZ } \\
(\mu \mathrm{g})\end{array}$ & $\begin{array}{c}\text { UVA } \\
(\mathrm{min})\end{array}$ & $\begin{array}{c}\mathrm{Trp}^{+} / \mathrm{plate} \\
(\mathrm{mean})\end{array}$ & $\begin{array}{c}\text { Induced } \\
\mathrm{Tr}^{+} / \text {plate }\end{array}$ & $\begin{array}{c}\text { Relative } \\
\text { mutagenicity } \\
(\%)\end{array}$ \\
\hline- & 0 & 0 & 102 & - & - \\
- & 150 & 0 & 100 & 0 & - \\
- & 0 & 10 & 103 & 1 & - \\
(control) & 150 & 10 & 684 & 582 & 100 \\
DNA (0.1 mg) & 150 & 10 & 694 & 592 & 101.7 \\
BSA $(0.1 \mathrm{mg})$ & 150 & 10 & 685 & 583 & 100.2 \\
Catalase $(0.1 \mathrm{mg})$ & 150 & 10 & 712 & 610 & 104.8 \\
SOD $(0.1 \mathrm{mg})$ & 150 & 10 & 677 & 575 & 98.8 \\
S9 (0.05 mL) & 150 & 10 & 728 & 626 & 107.6 \\
S9 mix $(0.5 \mathrm{~mL})$ & 150 & 10 & 149 & 47 & 8.1 \\
\hline
\end{tabular}

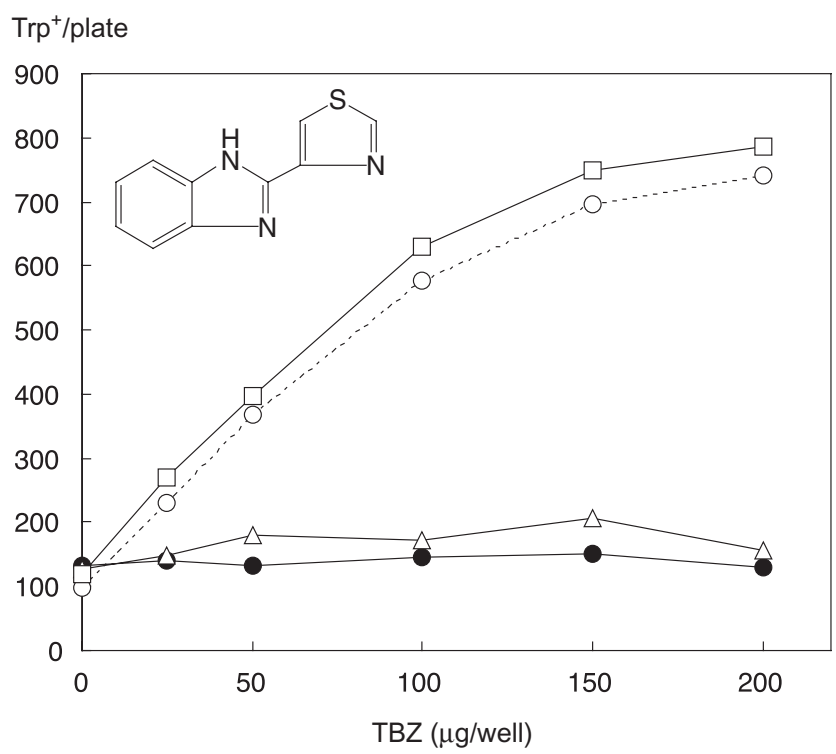

Fig. 1 Effect of S9 mix and co-factors on photo-mutagenicity of TBZ. UVA was irradiated for $10 \mathrm{~min}$. $\bigcirc$, control (buffer); $\square$, S9 fraction (50 $\mu \mathrm{L} /$ well); $\bigcirc$, S9 mix ( $0.5 \mathrm{~mL} /$ well); $\triangle$, co-factors solution $(0.5 \mathrm{~mL} /$ well $)$

Fig. 2 shows, equimolar NADH or NADPH suppressed the photo-mutagenicity of TBZ at a dose of $0.75 \mu \mathrm{mol}$, but oxidized forms of $\mathrm{NAD}^{+}$or $\mathrm{NADP}^{+}$were not. At a dose of $3 \mu \mathrm{mol} \mathrm{NAD}\left(\mathrm{NADP}^{+}\right)$, slight decrease in the number of $\mathrm{Trp}^{+}$revertants induced by TBZ with UVA was observed.

Since the reducing agents such as cysteine and glutathione did not inhibit the photo-mutagenicity of TBZ (data not shown), it was considered that the reducing potential of the compounds was not related to the inhibitory effects. It is known that $\mathrm{NADH}$ and $\mathrm{NADPH}$ have an absorption peak of $338 \mathrm{~nm}(\varepsilon=6,200)$, while TBZ has a peak of $302 \mathrm{~nm}(\varepsilon=24,530)$. Around $320-330 \mathrm{~nm}$, which is considered to be the wavelength responsible for the UVAactivation of TBZ, NADH and NADPH but not $\mathrm{NAD}^{+}$and $\mathrm{NADP}^{+}$showed high absorbance (data not shown). Thus, it is suggested that NADH and NADPH might be quenching UVA irradiation, and suppressed photo-mutagenicity of TBZ. The possibility that NADH and NADPH might interfere with UVA absorption by TBZ might be supported by an observation that an addition of pyridoxal $(\lambda \max =318 \mathrm{~nm}, \varepsilon=8,200)$ at $0.75-3 \mu \mathrm{mol}$ showed similar inhibitory effect on photo-mutagenicity of TBZ, as did NADH (data not shown).

We carried out further experiments with other photomutagenic agents, angelicin (UV absorption peak around $300 \mathrm{~nm}$ ) and chlorpromazine (UV absorption peak around 255 and $305 \mathrm{~nm}$ ). As shown in Fig. 3, the photo-mutagenicity of these compounds as well as TBZ was also suppressed in the presence of $0.1-1.6 \mu \mathrm{mol} \mathrm{NADH}$ in a dosedependent manner. Similar inhibition of photo-mutagenicity was observed by adding $\mathrm{NADPH}$, but not by $\mathrm{NAD}^{+}$or $\mathrm{NADP}^{+}$(data not shown). Thus, the use of NADH and NADPH as components of S9 mix is likely to inhibit UVAactivated photo-genotoxicity. In standard in vitro genotoxi- 


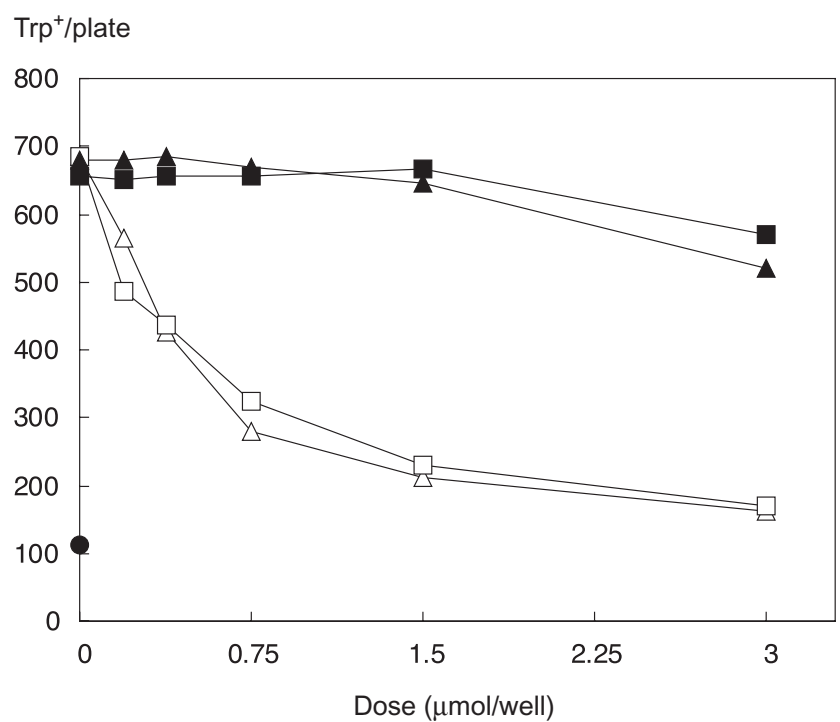

Fig. 2 Inhibitory effect of NADH and NADPH on photo-mutagenicity of TBZ. $\mathrm{NAD}^{+}(\mathbf{\Delta}), \mathrm{NADP}^{+}(\square), \mathrm{NADH}(\triangle)$, or NADPH $(\square)$ was added to the mixture of bacteria and TBZ $(0.75 \mu \mathrm{mol} /$ well) in $0.5 \mathrm{~mL}$ phosphate buffer and then the mixture was irradiated for $10 \mathrm{~min}$. control without TBZ

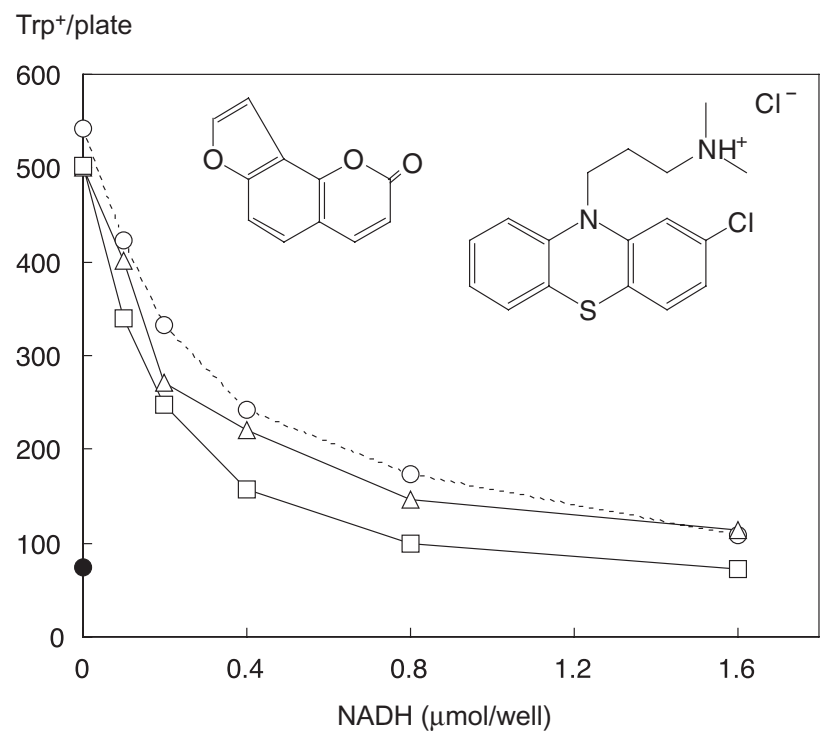

Fig. 3 Inhibition of photo-mutagenicity of TBZ, chlorpromazine, and angelicin by NADH. UVA was irradiated for $10 \mathrm{~min}$. $\bigcirc$, TBZ (100 $\mu \mathrm{g} /$ well); $\triangle$, angelicin (1 $\mu \mathrm{g} /$ well); $\square$, chlorpromazine (10 $\mu \mathrm{g} /$ well); , control

city tests, $0.5 \mathrm{~mL}$ of $\mathrm{S} 9 \mathrm{mix}$ is incorporated into the assay system. This amount of S9 mix contains $2 \mu \mathrm{mol}$ each of $\mathrm{NADH}$ and $\mathrm{NADPH}$ and that is enough for complete inhibition of TBZ photo-mutagenicity. On the other hand, S9 mix supplemented with $\mathrm{NAD}^{+}$and $\mathrm{NADP}^{+}$instead of $\mathrm{NADH}$ and NADPH was generally used in in vitro genotoxicity tests in USA (Ames et al., 1975; Maron and Ames, 1983). Therefore, we compared the effect of S9 mix containing $\mathrm{NAD}^{+}$and $\mathrm{NADP}^{+}$with the effects of $\mathrm{S} 9$ mix containing NADPH and NADH on photo-mutagenicity of
TBZ. UVA-induced photo-mutagenicity of TBZ was observed in the presence of $\mathrm{NAD}^{+} / \mathrm{NADP}^{+}$-based $\mathrm{S} 9$ mix, but not in $\mathrm{NADH} / \mathrm{NADPH}$-based S9 mix (Fig. 4). The slight decrease in photo-mutagenicity in the presence of $\mathrm{NAD}^{+} / \mathrm{NADP}^{+}$-based S9 mix compared with the phosphate buffer control may have been caused in part by the intracellular reduction of $\mathrm{NAD}^{+}\left(\mathrm{NADP}^{+}\right)$to $\mathrm{NADH}$ (NADPH) during the irradiation of $10 \mathrm{~min}$ or by metabolically detoxification of TBZ. 


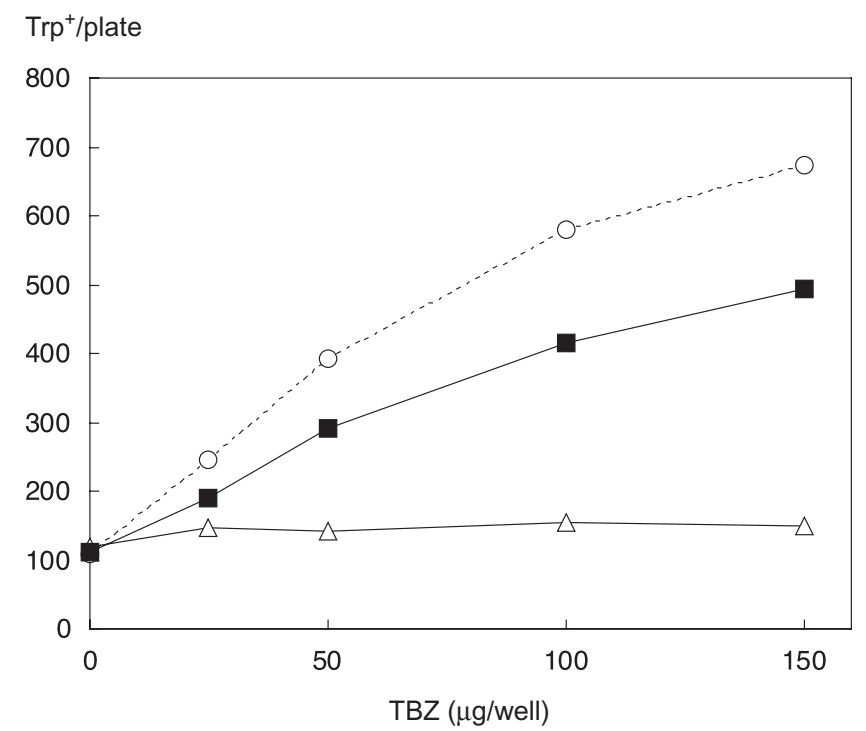

Fig. 4 Photo-mutagenicity of TBZ in the presence of S9 mix. UVA was irradiated for $10 \mathrm{~min} . \bigcirc$, control (buffer); $\mathbf{\square}, \mathrm{NAD}^{+}$ $/ \mathrm{NADP}^{+}$-based S9 mix, $\triangle$, NADH/NADPH-based S9 mix

\section{Discussion}

Several biological systems for detecting photo-mutagenic compounds have been described (Gocke et al., 2000; Marrot et al., 2001). Averbeck et al.(1993) reported that 1,6-dioxapyrene was strongly photo-mutagenic to $S$. typhimurium TA100 in the absence of S9 mix but less so in its presence. They assumed that 1,6-dioxapyrene was metabolically deactivated by S9 mix. It has been reported that all of the photo-mutagenic compounds were detected in the absence of S9 mix and their mutagenicity was generally disappeared or decreased in its presence (De Flora et al., 1989; Gocke et al., 2000), probably due to metabolic detoxification or, in another case, scavenging reactive oxygen radicals generated by UVA-irradiation by proteins in the S9 mix. Since no compounds that show clear photogenotoxic activity only when irradiated in the presence of S9 mix have been reported, the effects of S9 mix on photomutagens have not been fully examined. Under these circumstances, the Scientific Committee for Cosmetology (SSC) guideline on photo-genotoxicity testing in vitro has not included the use of an exogenous metabolic activation system (S9 mix), because there was no appropriate positive control compound (Loprieno, 1991).

TBZ also showed photo-mutagenicity following UVAirradiation in the absence of S9 mix but not in the presence of S9 mix. In our present study, NADH and NADPH were shown to inhibit photo-mutagenicity of angelicin and chlorpromazine as well as TBZ. On the other hand, oxidized forms of $\mathrm{NAD}^{+}$and $\mathrm{NADP}^{+}$did not inhibit photomutagenicity. Neither catalase nor SOD, reactive oxygen eliminating enzymes, suppressed the photo-mutagenicity of TBZ. We, therefore, suppose that NADH and NADPH interfere with UVA absorption by TBZ and suppress photo-mutagenicity. For the interpretation of decreased photo-mutagenicity in the presence of $\mathrm{S} 9 \mathrm{mix}$, we should consider the third possibility of quenching effects by $\mathrm{NADH}(\mathrm{NADPH})$ in addition to the metabolic detoxification of photo-mutagens and scavenging of oxygen radicals. In genotoxicity assays in vitro, either NADH/ $\mathrm{NADPH}$-based $\mathrm{S} 9$ mix or $\mathrm{NAD}^{+} / \mathrm{NADP}^{+}$-based $\mathrm{S} 9$ mix are commonly used. When photo-mutagens are being investigated in the presence of an exogenous metabolic activation system, the effect of UVA-absorbing compounds such as NADH and NADPH must be considered, and it seems that the use of $\mathrm{NAD}^{+} / \mathrm{NADP}^{+}$-based $\mathrm{S} 9$ mix would be better for photo-mutagenicity assays.

\section{Acknowledgments}

We thank Dr. Miriam Bloom for her critical reading of the manuscript. This work was supported in part by Grants-in Aid for Scientific Research from the Ministry of Education, Science, Sports, and Culture of Japan (15510061).

\section{References}

Ames, B.N., J. McCann and E. Yamasaki (1975) Methods for detecting carcinogens and mutagens with the Salmonella/mammalianmicrosome mutagenicity test, Mutat. Res., 31, 347-363.

Averbeck, D., K. Polasa, J.-P. Buisson, R. Bensasson, M. Rougée, J. Cadet, J.-L. Ravant, F. Perin, P. Vigny and P. Demerseman (1993) Photobiological activities of 1,6-dioxapyrene in pro- and eukaryotic cells, Mutat. Res., 287, 165-179.

Cancer Assessment Document, Evaluation of the carcinogenic potential of thiabendazole, 24 February 2000, Cancer Assessment Review Committee, Health Effects Division, Office of Pesticide 
Programs, EPA (HED Doc. No. 013840).

Ciulla, T.A., G.A. Epling and I.E. Kochevar (1986) Photoaddition of chlorpromazine to guanosine-5'-monophosphate, Photochem. Photobiol., 43, 607-613.

De Flora, S., A. Camoriano, A. Izzotti, F. D’Agonist and C. Bennicelli (1989) Photoactivation of mutagens, Carcinogenesis, 10, 10891097.

Gocke, E.(1996) Review of the genotoxic properties of chlorpromazine and related phenothiazines, Mutat. Res., 366, 9-21.

Gocke, E., L. Muller, P.J. Guzzie, S. Brendler-Schwaab, S. Bulera, C.F. Chignell, L.M. Henderson, A. Jacobs, H. Murli, R.D. Snyder and N. Tanaka (2000) Considerations on photochemical genotoxicity: report of the International Workshop on Genotoxicity Test Procedures Working Group, Environ. Mol. Mutagen., 35, 173-184.

Guideline for Screening Toxicity Testing in Chemicals, Section III. 1. Reverse Mutation Assay in Bacteria, Ministry of Labor, Japan (1988, revised in 1997).

Loprieno, N(1991) In vitro assay systems for testing photomutagenic chemicals, Mutagenesis, 6, 331-333.

Maron, D. and B.N. Ames (1983) Revised methods for the Salmonella mutagenicity test, Mutat. Res., 113, 173-215.

Marrot, L., J.P. Belaidi, C. Chaubo, J.R. Meunier, P. Perez and C. Agapakis-Causse (2001) Fluoroquinolones as chemical tools to define a strategy for photogenotoxicity in vitro assessment,
Toxicol. In Vitro, 15, 131-142.

Mudry de Pargament, M., M. Labal de Vinuesa and I. Larripa (1987) Mutagenic bioassay of certain pharmacological drugs: I. Thiabendazole (TBZ), Mutat. Res., 188, 1-6.

Oppenländer, T.(1988) A comprehensive photochemical and photophysical assay exploring the photoreactivity of drugs, Chimia, 42, 331-342.

Parry, J.M. and A. Sors (1993) The detection and assessment of the aneugenic potential of environmental chemicals: the European Community Aneuploidy Project, Mutat. Res., 287, 3-15.

Styles, J.A. and R. Garner (1974) Benzimidazolecarbamate methyl ester: evaluation of its effects in vivo and in vitro, Mutat. Res., 26, 177-187.

Venturini, S., M. Tamaro, C. Monti-Bragadin, F. Bordin, F. Baccicchetti and F. Carlassare (1980) Comparative mutagenicity of linear and angular furocoumarins in Escherichia coli strains deficient in known repair functions, Chem. Biol. Interact., 30, 203-207.

Venturini, S., M. Tamaro, C. Monti-Bragadin and F. Carlassare (1981) Mutagenicity in Salmonella typhimurium of some angelicin derivatives proposed as new monofunctional agents for the photochemotherapy of psoriasis, Mutat. Res., 88, 17-22.

Watanabe-Akanuma, M., T. Ohta and H. Yamagata (2003) Photomutagenicity of thiabendazole, a postharvest fungicide, in bacterial assays, Environ. Mol. Mutagen., 41, 92-98. 